UNDERGRADUATE RESEARCH IN NATURAL AND CLINICAL SCIENCE AND TECHNOLOGY (URNCST) JOURNAL Read more URNCST Journal articles and submit your own today at: https://www.urncst.com

\title{
Combating Antimicrobial Resistance: Assessing Efflux Pump Deficient Environments in Neisseria gonorrhoeae and the Masking Effect on Antimicrobial-Resistant Mutations
}

Kaitlyn A. Jackson, BSc [1]*, Tiffany Ayoub, BSc [1], Julia E. Pearson, BSc [2], Julie A. Richmond, BSc [1]

[1] Department of Biomedical Sciences, University of Guelph, Guelph, Ontario, Canada N1G 2W1

[2] Department of Molecular and Cellular Biology, University of Guelph, Guelph, Ontario,

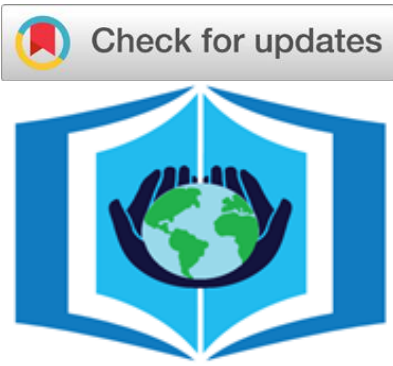

URNCST Journal

"Research in Earnest" Canada N1G 2W1

*Corresponding Author: kjacks13@uoguelph.ca

\begin{abstract}
Introduction: Antimicrobial resistance (AMR) is a global emergency that involves the process of microbes gaining resistance to antimicrobials. A specific example of this is Neisseria (N.) gonorrhoeae gaining resistance to azithromycin, which can be caused by mutations at ribosomal sites. New research suggests that manipulating the bacteria to create a drug efflux pump deficiency will "mask" the effects of AMR mutations when introduced to antibiotic drugs, compared to that of a drug efflux pump proficient environment. This proposal aims to investigate the effects of a drug efflux pump deficient environment compared to a proficient environment on azithromycin drug efficacy in $N$. gonorrhoeae with an AMR ribosomal mutation. It is hypothesized that AMR mutations can be masked through gene knockout causing MtrCDE efflux pump deficient environments of $N$. gonorrhoeae.

Methods: Aim 1 consists of inducing a ribosomal mutation that incurs resistance to azithromycin in $N$. gonorrhoeae strains using CRISPR genome editing in groups A and B. Aim 2 will utilize CRISPR-Cas9 to delete the mtrE gene in $N$. gonorrhoeae, rendering the MtrCDE efflux pump deficient, creating an efflux pump deficient environment in the bacteria of groups B and D. Aim 3 will determine the difference in susceptibility of $N$. gonorrhoeae towards azithromycin between efflux pump deficient and proficient environments, using disk diffusion and zone of inhibition.

Results: We expect Group A will have a smaller diameter zone of inhibition exhibiting azithromycin resistance, while Groups B, C and D will result in a larger diameter exhibiting azithromycin susceptibility.

Discussion: We anticipate that Group A will have the smallest diameter zone of inhibition due to the azithromycin resistant mutation and proficient efflux pump environment. We expect Group B will have the largest diameter, demonstrating that $N$. gonorrhoeae became susceptible to azithromycin with the deficient efflux pump environment masking the azithromycin resistant mutation. Group C (proficient pump) and D (deficient pump) are both wild-type strains therefore we predict they will have larger diameters due to their natural susceptibility to azithromycin.

Conclusion: The proposed experiment could help uncover the molecular mechanisms behind masking, which could consequently provide a gateway towards effective strategies to combat AMR.
\end{abstract}

Keywords: antimicrobial resistance; azithromycin; CRISPR-Cas9; drug efflux pumps; genome sequencing; Neisseria gonorrhoeae; PCR; ribosomal mutation

\section{Introduction}

Antimicrobial resistance (AMR) is an increasing global crisis, characterized by changes in microbes that result in resistance to widely used antibiotics [1-3]. The rise in AMR is due to a variety of factors, such as through agriculture, although in the clinical setting it primarily results from the overuse of antibiotics [1-3]. For example, the sexually transmitted infection gonorrhea (caused by the Gramnegative bacteria Neisseria (N.) gonorrhoeae) is increasingly resistant to the majority of antibiotics and is therefore a pressing global concern [4]. A variety of antibiotics are currently available to combat gonorrhea, the preferred combination being azithromycin, one of the macrolide antibiotics, together with a cephalosporin [4,5]. While azithromycin remains one of the primary antibiotics used to treat gonorrhea, it is increasingly ineffective due to AMR. Thus, it has become vitally important to explore alternative therapies [6].

The predominant mechanism by which $N$. gonorrhoeae acquires resistance to agents like azithromycin is through 
UNDERGRADUATE RESEARCH IN NATURAL AND CLINICAL SCIENCE AND TECHNOLOGY (URNCST) JOURNAL Read more URNCST Journal articles and submit your own today at: https://www.urncst.com

mutations at ribosomal sites that alter the drug target $[1,7]$. Drug efflux pumps, which allow Gram-negative bacteria to regulate their internal environment by pumping out antimicrobial agents, also contribute to azithromycin resistance by lowering the intracellular concentration of the antibiotic [7]. This provides a potential drug target, since inhibiting the drug efflux pump may allow intracellular antibiotic concentrations to rise [8]. However, although previous research regarding inhibiting efflux pumps has focused on microbe susceptibility to antibiotics that were initially a victim of the active efflux pumps, this study focuses on another potential benefit to inhibition of efflux pumps - masking other modes of antimicrobial resistance, including ribosomal mutations $[9,10]$. In essence, inhibiting efflux pumps creates a drug efflux pump deficiency in bacteria [10]. When introducing antibiotic drugs to a bacterium with a ribosomal AMR mutation, the drug efflux pump deficient environment masks the effects of the AMR mutation, compared to that of a drug efflux pump proficient environment [10]. Normally, an efflux pump actively pumps out antimicrobials and other agents to prevent intracellular accumulation which can cause adverse effects inside the cell [9]. An efflux pump is susceptible to an antimicrobial drug when the efflux pump does not interact with the drug therefore the efflux pump does not pump the antimicrobial drug out of the cell [9]. This is the same with the MtrCDE efflux pump and azithromycin seeing as we chose azithromycin because it does not interact with the MtrCDE efflux pump causing this natural susceptibility to the drug [9]. The drug does not target the efflux pump to make it no longer functional [9]. By knocking out the outer membrane we will create a deficient efflux pump which masks the antimicrobial resistant mutation [9]. So far, however, the concept that "masking" may restore antibiotic sensitivity has only been tested with respect to erythromycin activity in Escherichia (E.) coli $[10]$.

The term "masking" in this context was first introduced by Fange et al. using erythromycin on E. coli, who described it as a phenomenon where, in a drug efflux pump deficient background, the drug susceptibility is identical for wild-type and target-mutated strains at all external drug concentrations [9]. Because the molecular mechanism behind masking is unclear, a molecular term has not been designated by scientists to describe this effect.

This proposal seeks to test the hypothesis that a similar approach will restore azithromycin sensitivity in an otherwise resistant strain of the important human pathogen,
N. gonorrhoeae. Specifically, we will focus on the 20870 strain of $N$. gonorrhoeae containing the azithromycin resistant $\mathrm{C} \rightarrow \mathrm{T}$ ribosomal mutation at position 2611 position 2599 in alleles 1 and 2 and position 2605 in allele 4 [11]. Azithromycin binds to the entrance of the peptide exit tunnel of the (50S) ribosomal unit [11]. Azithromycin, along with other macrolides, bind in the proximity of the peptide-transferase centre [11]. Azithromycin blocks the entrance of the nascent chain to the peptide exit tunnel instead of inhibiting the peptide bond formation rendering the cells resistant to azithromycin [11]. The MtrCDE efflux pump, a member of the resistance-nodulation-cell division superfamily (RND) in N. gonorrhoeae, will be used due to its lack of effect on azithromycin efficacy [12]. Knocking out the $m t r E$ gene that encodes for the MtrCDE efflux pump outer membrane subunit will cause a drug-efflux pump deficient environment, as seen in Figure 1 [4,9-11,13]. Antibiotics such as azithromycin inhibit gramnegative bacteria such as $N$. gonorrhoeae less effectively due to the outer membrane which essentially acts as a barrier to the pump. Knocking out this barrier via the $m t r E$ gene, would be the best approach to deem the efflux pump deficient in comparison to the other genes [9-11].

Expression of the MtrCDE efflux pump is mediated by MtrR (a repressor from the TetR family) and MtrA - an activator from the AraC family [13]. Currently, changes in expression in the microbe occur via induced mutation or alteration. In wildtype strains of $N$. gonorrheae, MtrCDE efflux pump expression is low [13]. However, in various mutated strains that impact the viability of the MtrR protein, the expression of the efflux pump is high due to lack of repression [13]. This increase in MtrCDE efflux pump expression due to lack of MtrR protein expression results in heightened resistance to a variety of antimicrobials [13]. Strain 20870 was selected for its ribosomal AMR mutation, which is unrelated to the MtrCDE efflux pump and its repressor [13]. Thus, in regard to the efflux pump, this strain will mimic that of the wild type.

This experimental design creates an ideal model for investigating the concept of masking. This study will investigate the effects of a drug efflux pump deficient environment compared to a drug efflux pump proficient environment on azithromycin drug efficacy in $N$. gonorrhoeae with an AMR ribosomal mutation [4,9-11,13]. It is hypothesized that AMR can be mitigated through gene knockout of the MtrCDE efflux pump in N. gonorrhoeae, restoring azithromycin sensitivity. 
UNDERGRADUATE RESEARCH IN NATURAL AND CLINICAL SCIENCE AND TECHNOLOGY (URNCST) JOURNAL Read more URNCST Journal articles and submit your own today at: https://www.urncst.com

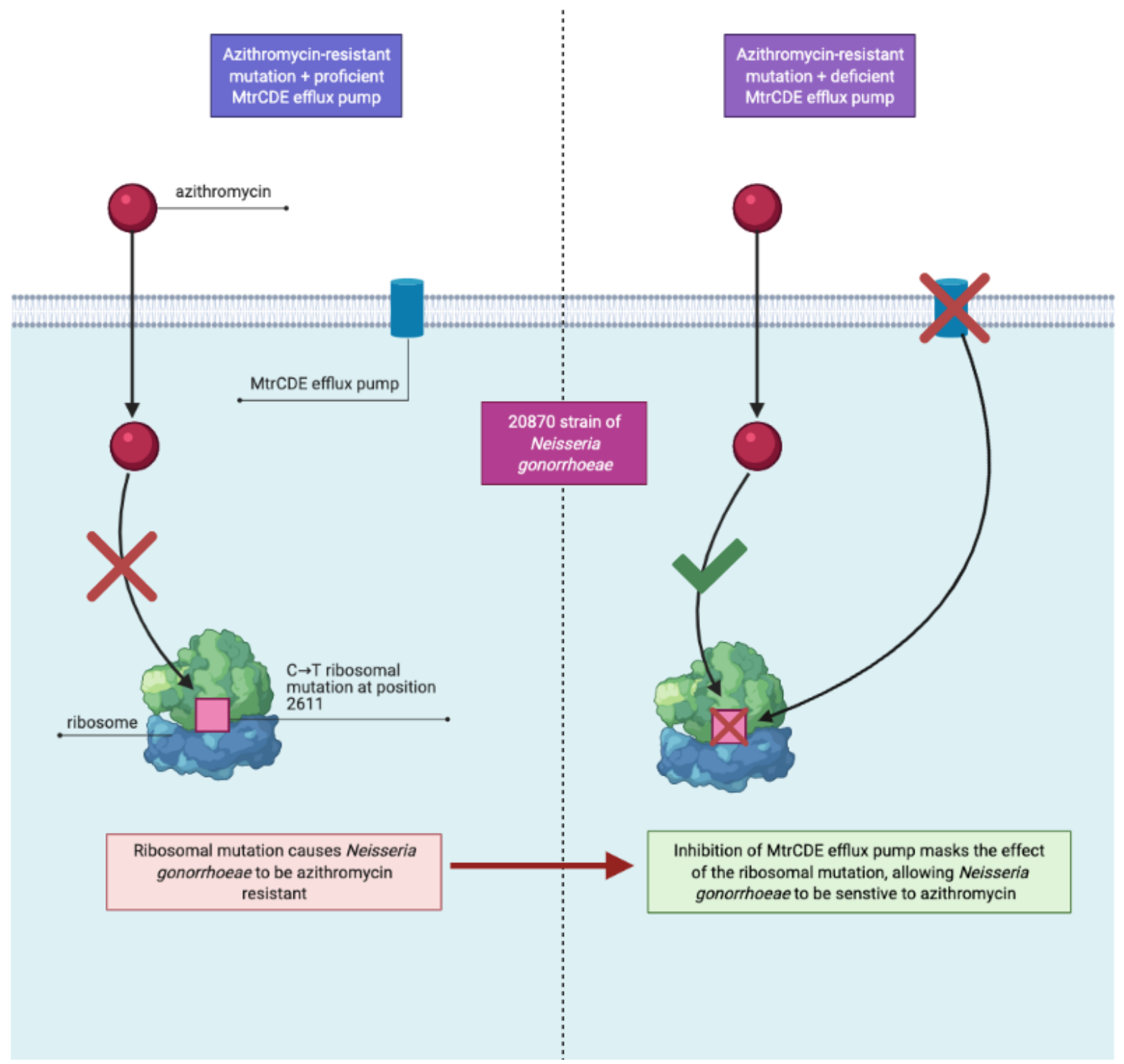

Figure 1. Gene knockout of the MtrCDE efflux pump in 20870 strain of $\mathrm{N}$. gonorrhoeae containing the azithromycin resistant $\mathrm{C} \rightarrow \mathrm{T}$ ribosomal mutation at position 2611 , restoring azithromycin sensitivity [4,9-11,13].

\section{Methods}

Standard Biosafety in Microbiological and Biomedical Laboratories procedures will be followed [14]. Appropriate biosafety and pathogen handling training modules will be completed prior to experimental commencement [15]. $N$. gonorrheae is transmitted through direct skin contact, contact with an infected animal, and direct contact with mucous membranes [14]. All researchers involved in the conduction of this experiment will be educated on the risks and safety protocols for handling $N$. gonorrheae in a laboratory setting. Lab coat, gloves and eye protection will be used when direct skin contact with the bacteria and/or infected materials in unavoidable [14]. Biosafety Level 2 practices will be utilized when handling $N$. gonorrheae
[15]. All researchers will be made aware of the first aid procedures and safety measures to impose if exposed to $N$. gonorrheae $[14,15]$.

There are 3 specific aims that this proposal is looking to achieve by the conclusion of the research. Aim 1 will consist of inducing an azithromycin-resistant mutation in $N$. gonorrhoeae; Groups A (AMR ribosomal mutation, proficient efflux pump) and B (AMR ribosomal mutation, deficient efflux pump). Aim 2 will consist of knocking out the genes encoding for the MtrCDE efflux pump in $N$. gonorrhoeae to create an efflux pump deficient environment in Groups B (AMR ribosomal mutation, deficient efflux pump) and D (Wild type, deficient efflux pump). 


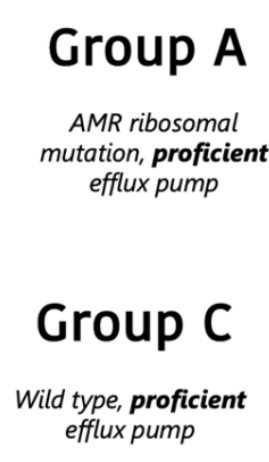

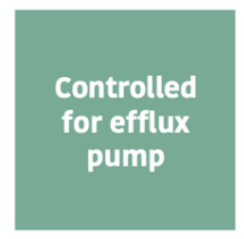
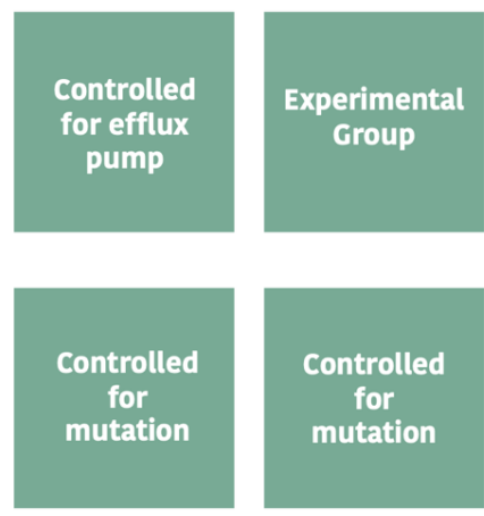

\section{Group B}

\author{
AMR ribosomal \\ mutation, deficient \\ efflux pump \\ Group D \\ Wild type, deficient \\ efflux pump
}

Figure 2. Summary of experimental groups.

Aim 3 will consist of determining azithromycin resistance differences between deficient and proficient efflux pump environments via disk-diffusion. A summary of the experimental groups are outlined in Figure 2.

\section{Aim 1: Inducing azithromycin-resistant mutation in $N$.} gonorrhoeae; Groups A and B

In order to induce $N$. gonorrhoeae resistance to azithromycin, CRISPR genome editing will be used to introduce a $\mathrm{C} \rightarrow \mathrm{T}$ ribosomal mutation at position 2611 , which is a confirmed azithromycin resistant mutation in $N$. gonorrhoeae, where studies have reiterated this region in the genome as important [11]. Aim 1 ensures that the mechanism of resistance is uniform for the initial populations of bacteria. Otherwise, the mechanism of resistance may vary in each resistant strain, impacting the results of this proposed study. Aim 1 could be eliminated with the use of pre-resistant mutants but their genetics would still require validation for consistency.

Class 2 Clustered Regularly Interspaced Short Palindromic Repeat (CRISPR) systems have been modified for genome editing by utilizing 2 components, a guide RNA (gRNA or sgRNA) and a CRISPR-associated endonuclease (Cas protein) [16]. The CRISPR-Cas9 system is able to efficiently work in a laboratory setting, by creating a small piece of RNA with a guide sequence that binds to a specific target sequence of DNA in the targeted genome [16]. The RNA then binds to the Cas9 enzyme, and the enzyme creates a targeted double-stranded break [16]. Once cut, the cells own DNA can be used to make changes by gene knock-in and the introduction of precise point mutations [16]. This can be achieved by homology-directed repair (HDR) using a donor DNA template which is how we will induce a C-T mutation at position 2611 in $N$. gonorrhoeae [16].

In the interest of validating the presence of azithromycin-resistant mutants, PCR and Sanger sequencing will be used to validate the intended mutation and determine if the process introduced unexpected pleiotropic mutations elsewhere in the genome $[13,17]$.
Following Sanger sequencing, GeneBLAST will be employed to generate and compare gene sequences of the azithromycin-resistant mutants and wild type (WT) strains $[19,20]$. This would verify if the pleiotropic mutation detected was that of the 23S rRNA mutation at position 2611, resulting in an azithromycin-resistant mutant [11]. Azithromycin exposure is not used to verify successful mutation because other mutations in genome must be determined before moving forward with Aim 2. Aim 1 ensures the division between mutant and wild type strains for elimination based on genetics. It is important to refrain from exposing the bacteria to azithromycin until it can be measured in Aim 3 as environmental stress can induce inconsistent genetic variability.

Aim 2: Knockout of genes encoding for MtrCDE efflux pump in N. gonorrhoeae; Groups B and D

A minimum of three biological replicates will be utilized [21]. Each biological replicate will consist of four treatment groups, two with the $N$. gonorrhoeae azithromycin resistant mutation as described in Aim 1, and two without. Group A and B will consist of the mutation, possessing a proficient MtrCDE efflux pump environment and a deficient MtrCDE efflux pump environment, respectively $[5,10,11]$. Group $\mathrm{C}$ and $\mathrm{D}$ will be a WT without a mutation, with the same efflux pump conditions as Group A and B. Prior to creating an efflux pump deficient environment, efflux ability will be measured in all the groups by recruiting fluorescence dye and recording the change in fluorescence over time as the dye is pumped out of the cells [22]. Once proficiency is confirmed, to create the MtrCDE deficiency in Groups B and D, we will be utilizing CRISPR-Cas9 genome editing to knockout the $m t r E$ gene (Figure 3) encoding for the outer membrane of the MtrCDE pump in N. gonorrhoeae (Figure 4), causing an efflux pump deficient environment $[10,11]$. Generating gene knockout in a target sequence can be achieved by co-expressing an endonuclease, such as Cas9, and a gRNA specific to the targeted gene [20]. The Cas9 protein and gRNA form a complex, while Cas9 undergoes a 
conformation change once bound to the gRNA that shifts the molecule form an inactive to an active conformation [20]. Cas9 will only cleave a locus if the gRNA spacer sequence shares homology with the target DNA [20]. Once the Cas9-gRNA complex binds a DNA target, the sequence will anneal to the target DNA, in a 3'-5' direction [20]. The end result of Cas9-mediated DNA cleavage is a doublestrand break (DSB) within the targeted DNA [20]. The DSB is then repaired by the non-homologous end joining (NHEJ) pathway, which causes small nucleotide insertions or deletions (indels) at the DSB site, with the ideal end result being a loss-of-function mutation within the targeted gene [20].

Once CRISPR-Cas9 knockout has been completed, PCR followed by Sanger sequencing will be used to verify $m$ trE gene deletion, in addition to measuring protein expression by performing a Western blot [24]. We will then measure efflux again using fluorescence dye to ensure the efflux pumps are deficient in groups B and D [22]. In order to measure efflux through RND efflux pumps, Nile Red and 1,2 '-dinaphthylamine dyes will be used due to their periplasmic nature which is ideal [22].

In their natural environment, bacterial stressors trigger error prone DNA polymerases and the movement of mobile genetic elements [25]. Thus, inducing multiple mutations does not present a threat to the efficiency of the bacteria being studied as natural genetic variability for resistance already occurs simultaneously. Elevated mutation rates simply accelerate the acquisition of resistance. Aim 3 ensures consistency in mutated and wild-type strains.

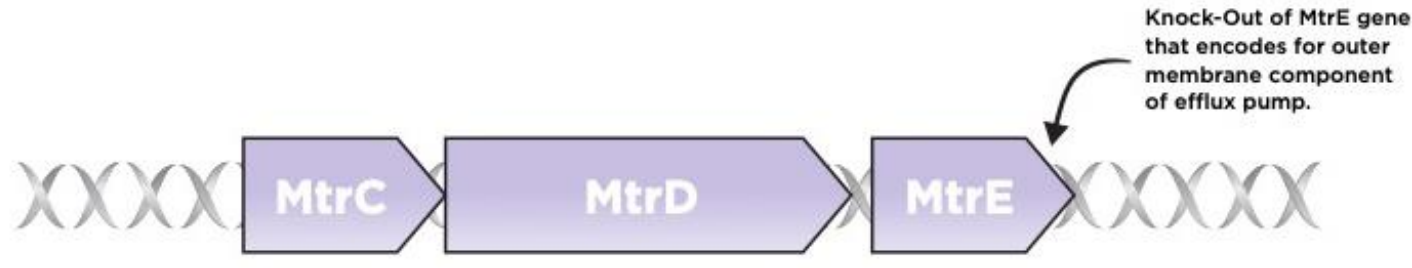

Figure 3. Mtr locus of $N$. gonorrhoeae displaying the operon encoding for the drug efflux pump including genes $m t r C$, $m t r D$, and $\operatorname{mtr} E[12,13]$.

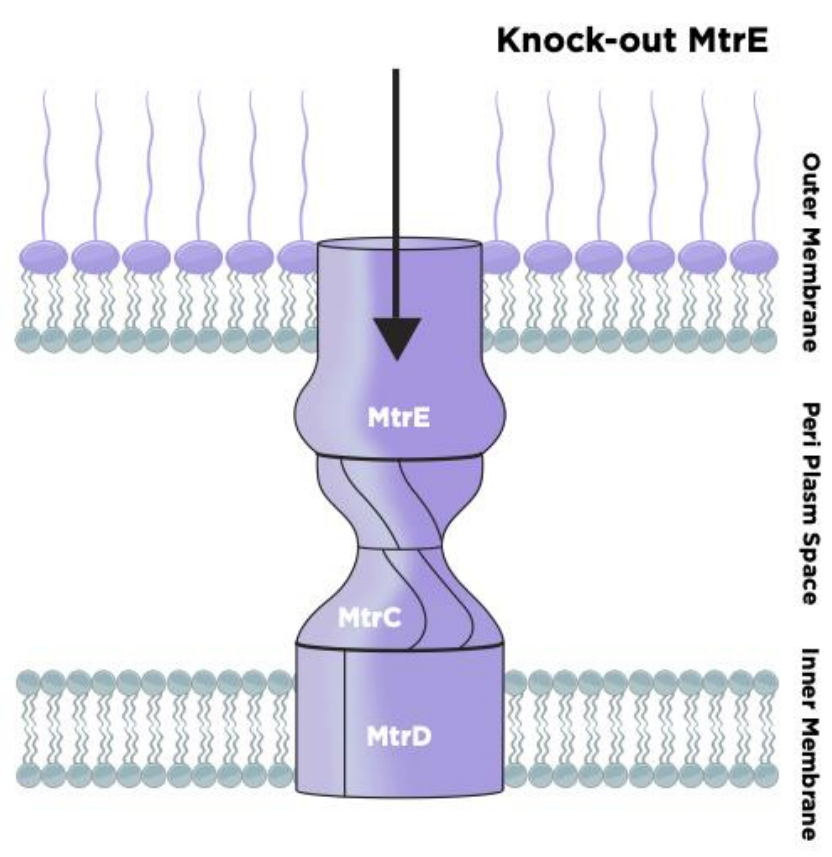

Figure 4. The MtrC-MtrD-MtrE pump, showing the position of $\mathrm{MtrD}$ in the inner membrane, MtrC in the periplasmic space, and MtrE in the outer membrane $[12,14]$.
Aim 3: Determining resistance differences via diskdiffusion; Groups A, B, C and D

To determine if a difference in resistance to azithromycin exists between all groups, standard KirbyBauer Disk Diffusion Antimicrobial Susceptibility Testing Protocol will be used [26,27]. One population of each group will be plated at consistent concentrations and the disks are to be stored at $35^{\circ} \mathrm{C}$ in an air incubator for 16 to 18 hours before measurement [27]. Where larger diameters infer greater resistance, measuring the zone of inhibition following disk diffusion will allow us to determine the difference in susceptibility of $N$. gonorrhoeae towards azithromycin between all groups [26,27]. Analysis of variance (ANOVA) will be used to determine statistical significance, referenced to a p-value of 0.05 , which will allow us to determine a numeric difference in susceptibility of $N$. gonorrhoeae towards azithromycin between all 4 of our treatment groups [6]. According to similar research, the sgRNA-Cas9 RNPs were shown to cleave the target chromosomal DNA between 12 and 24 hours after delivery and the frequency of gene editing reaches a plateau after 1 day [20]. Based on the type of CRISPR edits, it should take a total 1-2 weeks to complete [20]. The timeline for the total experiment is an estimated 2-3-week period in the event that all experimentation is successful [20]. A summary of the experimental design is outlined in Figure 5. 
UNDERGRADUATE RESEARCH IN NATURAL AND CLINICAL SCIENCE AND TECHNOLOGY (URNCST) JOURNAL Read more URNCST Journal articles and submit your own today at: https://www.urncst.com

(1)

(3)

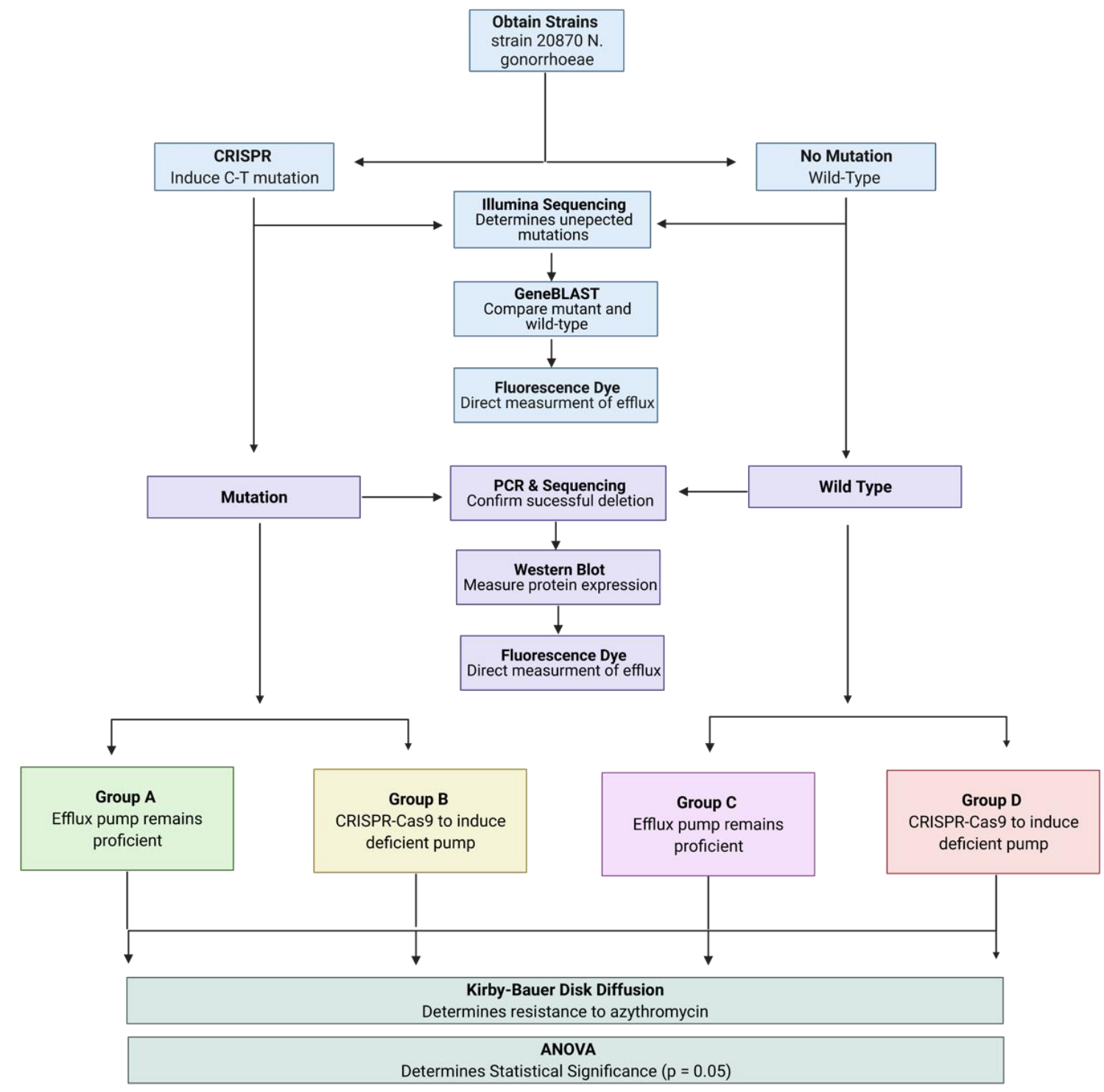

Figure 5. Summary of the experimental design.

\section{Results}

We anticipate the results of our study will illustrate that Group A, which possesses the AMR ribosomal mutation and proficient efflux pump environment, will be resistant to azithromycin. Moreover, we expect Group B, which possesses the AMR ribosomal mutation and deficient efflux pump environment, will be susceptible to azithromycin. Additionally, Group C, which consists of the wild-type strain with a proficient efflux pump environment, is predicted to be susceptible to azithromycin, due to its lack of the AMR ribosomal mutation. Lastly, we anticipate Group D, which also consists of the wild-type strain with a deficient efflux pump environment instead, will also be susceptible to azithromycin, for the same reason as Group C. The expected outcomes are summarized in Figure 6 . This paper does not contain numerical results, as this a proposal for potential prospective studies. 

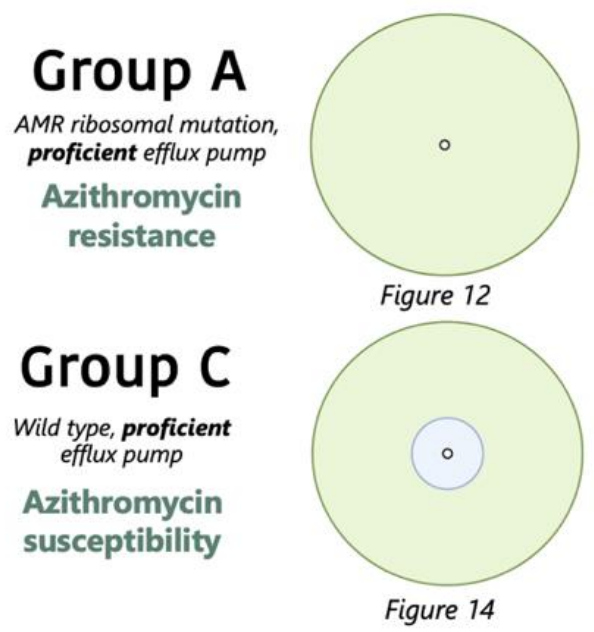

Figure 6. Summary of the expected outcomes.

\section{Discussion}

We anticipate that Group A's zone of inhibition will have a smaller diameter than the rest of the groups. Since Group A possesses both a proficient efflux pump environment and azithromycin resistant mutation, its characteristics are analogous to a typical antimicrobial resistant strain $[9,10,25]$. In essence, both the mutation and the efflux pump will contribute to the inefficacy of azithromycin, leading us to predict that it will have the smallest diameter compared to the other groups $[6,9,10,25]$. Group B is the focus of our study, which we desire to alter in order to go from resistant to azithromycin to susceptible. This will provide a basis for azithromycin to remain a successful treatment of gonorrhea, even in the event that there are azithromycin resistant mutations present. We anticipate Group B's zone of inhibition will have a larger diameter, demonstrating that $N$. gonorrhoeae is susceptible to azithromycin. This outcome would be a result of the efflux pump deficient environment masking the azithromycin resistant mutation, providing support for our proposed hypothesis [5,9-11]. Group C and D are both wild-type strains, therefore we expect they will have larger diameters due to their natural susceptibility to azithromycin. In the case of Group D, the deficient efflux pump environment would not be enough to result in resistance, due to the MtrCDE efflux pump being susceptible to azithromycin [5,9-11]. In the presence of the AMR mutation, the MtrCDE efflux pump may help contribute to the resistance of azithromycin, but without the mutation, this pump will remain dormant due to its overall susceptibility to azithromycin, thus explaining the proposed outcome for Group D [5,9-11].

Antimicrobial resistance is caused by a wide variety of factors - not limited to efflux pumps - one main contender being that of antimicrobial resistant mutations [1-3]. In many cases, antibiotics become ineffective not due to efflux

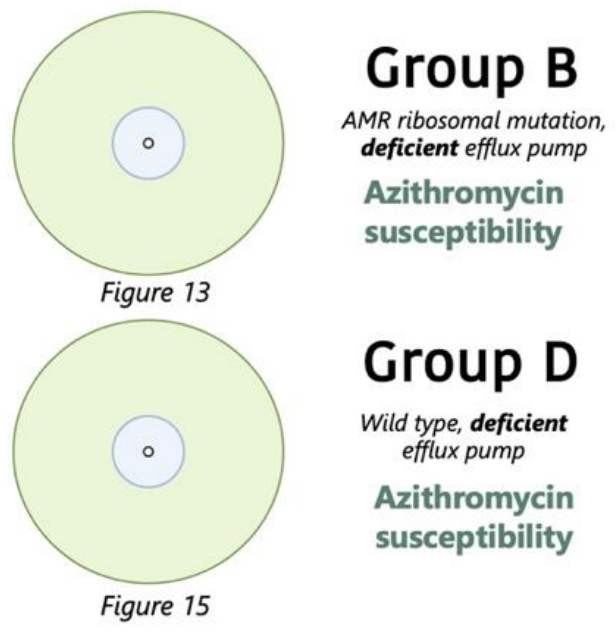

pumps, but because of the aforementioned mutations [1,7]. This proposal seeks to test the hypothesis that AMR mutations can be prevented from effectiveness without being directly targeted.

Prior experimentation has demonstrated the potential for inhibition of efflux pumps to mask the effects of AMR mutations $[9,10]$. In this scenario, the efflux pump being studied is one that has no influence on the efficacy of the antibiotic intervention selected - in essence, its presence causes no disruption to the process of destruction imposed upon the microbe by the antibiotic [9]. The desired environment includes an efflux pump - where, without mutation, the microbe would remain susceptible to the antibiotic - and an AMR mutation that is the main contributing factor causing resistance [9,10]. Preceding investigations have demonstrated the viability of this hypothesis in E. coli using erythromycin as the intervention, however, a similar approach has not been conducted in respect to $N$. gonorrheae $[9,10]$. Thus, this proposal seeks to determine if a similar hypothesis will prove efficacious in bacteria other than E. coli, such as $N$. gonorrheae.

This research will contribute to determining the underlying molecular mechanism of masking by finding a pattern or lack thereof between $N$. gonorrheae and E. coli with an AMR mutation and efflux pump inhibition. With the current hypothesis only being tested in $E$. coli, it is difficult to discern whether the molecular basis is specific to $E$. coli or can be generalized to other bacteria as well. Conducting research with a similar hypothesis in regard to varying bacteria will uncover more evidence for the specific causes. Once the molecular mechanism of masking is determined, a world of possibility will be unveiled regarding the fight against AMR [10]. The novelty of this study is both looking at efflux pump inhibition in a different light than previously studied and focusing this light on $N$. gonorrheae. This 
UNDERGRADUATE RESEARCH IN NATURAL AND CLINICAL SCIENCE AND TECHNOLOGY (URNCST) JOURNAL Read more URNCST Journal articles and submit your own today at: https://www.urncst.com

research could be of significant contribution to the field by determining a new way efflux pump inhibition can be of use against AMR [1,10].

All in all, although there is currently little known about the molecular mechanisms of masking, this study could provide further basis for determining the underlying mechanisms, and subsequently could inform future strategies to combat AMR [10].

\section{Conclusions}

Overall, this methodology has been successful in the past with E. coli, therefore we anticipate it will be successful with $N$. gonorrhoeae. Knocking out the MtrE subunit may not completely inhibit the effects of the pump, which could be addressed by inducing alternative mutations in other pump subunits. In addition, the idea of masking seen in Fange et al. was done with a different antimicrobial agent, Escherichia coli, and its corresponding efflux pump. Therefore, it may be a possibility that their methodology cannot be translated exactly to azithromycin. Similarly, the mechanism behind masking is still not yet understood which has the potential to cause problems when trying to adapt this methodology to other bacteria.

The proposed experiments will aid the understanding of developing strategies targeted against AMR by emphasizing a novel avenue of research on the alternative benefits of efflux pump deficiencies, specifically in $N$. gonorrhoeae. Future studies should focus on translating the outcomes of our findings to an animal model of infection that better emulates the clinical effects of AMR as well as determining the molecular mechanisms behind masking.

\section{List of Abbreviations Used}

AMR: antimicrobial resistance

ANOVA: analysis of variance

Cas9: CRISPR associated protein 9

CRISPR: clustered regularly interspaced short palindromic repeats

CRISPR-Cas9: clustered regularly interspaced short

palindromic repeats and CRISPR-associated protein 9

DNA: deoxyribonucleic acid

DSB: double-strand breaks

E. coli: Escherichia coli

gRNA: genomic DNA

HDR: homology directed repair

NHEJ: non-homologous end joining

N. gonorrhoeae: Neisseria gonorrhoeae

PCR: polymerase chain reaction

RND: resistance-nodulation-division

sgRNA: single guide RNA

sgRNA-Cas9: single guide RNA and CRISPR-associated

protein 9

WT: wild type

\section{Conflicts of Interest}

The authors declare that they have no conflict of interests.

\section{Ethics Approval and/or Participant Consent}

This prospective study will not require ethics approval. This study does not address, utilize, or consider any methodology relating to humans or animals in any capacity, nor are there any other ethical considerations.

\section{Authors' Contributions}

KAJ: Contributed to the planning and design of the study, drafted, and revised the manuscript, and gave final approval of the version to be published.

TA: Contributed to the planning and design of the study, drafted, and revised the manuscript, and gave final approval of the version to be published.

JEP: Contributed to the planning and design of the study, drafted, and revised the manuscript, and gave final approval of the version to be published.

JAR: Contributed to the planning and design of the study, drafted, and revised the manuscript, and gave final approval of the version to be published.

\section{Acknowledgements}

We would like to extend our gratitude to Dr. Neil MacLusky and Dr. Georgina Cox for assistance and directive guidance throughout the development stages of this project. We would also like to express our appreciation for Ramy Ayoub and Steven De Michino for their extensive support and advice throughout the entire process. Figures 1 , $\underline{2}, \underline{5}$, and $\underline{6}$ were created using BioRender.com. Figures 3 and $\underline{4}$ were created by $3 \mathrm{~A}$ Graphics Corporation.

\section{Funding}

This study was not funded.

\section{References}

[1] Prestinaci F, Pezzotti P, Pantosti A. Antimicrobial resistance: A global multifaceted phenomenon. Pathogens and Global Health. 2015;109(7):309-18. https://doi.org/10.1179/2047773215y.0000000030

[2] Mani-Loh C, Mamphweli S, Meyer E, Okoh A. Antibiotic use in agriculture and its consequential resistance in environmental sources: Potential public health implications. Molecules. 2018;23(4):795. https://doi.org/10.3390/molecules23040795

[3] Ilić K, Jakovljević E, Škodrić-Trifunović V. Socialeconomic factors and irrational antibiotic use as reasons for antibiotic resistance of bacteria causing common childhood infections in primary healthcare. European Journal of Pediatrics. 2011;171(5):767-77. https://doi.org/10.1007/s00431-011-1592-5

[4] Golparian D, Shafer WM, Ohnishi M, Unemo M. Importance of multidrug efflux pumps in the antimicrobial resistance property of clinical multidrugresistant isolates of Neisseria gonorrhoeae. Antimicrobial Agents and Chemotherapy. 2014;58(6):3556-9. https://doi.org/10.1128/aac.00038$\underline{14}$ 
UNDERGRADUATE RESEARCH IN NATURAL AND CLINICAL SCIENCE AND TECHNOLOGY (URNCST) JOURNAL Read more URNCST Journal articles and submit your own today at: https://www.urncst.com

[5] Leclercq R, Courvalin P. Bacterial resistance to macrolide, lincosamide, and streptogramin antibiotics by target modification. Antimicrobial Agents and Chemotherapy. 1991;35(10):1267-72. https://doi.org/ 10.1128/aac.35.10.2165

[6] Tuite AR, Gift TL, Chesson HW, Hsu K, Salomon JA, Grad YH. Impact of rapid susceptibility testing and antibiotic selection strategy on the emergence and spread of antibiotic resistance in gonorrhea. The Journal of Infectious Diseases. 2017;216(9):1141-9. https://doi.org/10.1093/infdis/jix450

[7] Soto SM. Role of efflux pumps in the antibiotic resistance of bacteria embedded in a biofilm. Virulence. 2013;4(3):223-9. https://doi.org/10.4161/ viru. 23724

[8] Marshall RL, Lloyd GS, Lawler AJ, Element SJ, Kaur J, Ciusa ML, et al. New multidrug efflux inhibitors for Gram-negative bacteria. mBio. 2020;11(4). https://doi.org/10.1128/mBio.01340-20

[9] Fange D, Nilsson K, Tenson T, Ehrenberg M. Drug efflux pump deficiency and drug target resistance masking in growing bacteria. Proceedings of the National Academy of Sciences of the United States of America. 2009;106(20):8215-20. https://doi.org/10 $.1073 /$ pnas.0811514106

[10] Lovmar M, Nilsson K, Lukk E, Vimberg V, Tenson T, Ehrenberg M. Erythromycin resistance by L4/L22 mutations and resistance masking by drug efflux pump deficiency. EMBO Journal. 2009;28(6):736-44. https://doi.org/10.1038/emboj.2009.17

[11] Ng LK, Martin I, Liu G, Bryden L. Mutation in 23S rRNA associated with macrolide resistance in Neisseria gonorrhoeae. Antimicrobial Agents and Chemotherapy. 2002;46(9):3020-5. https://doi.org/10 .1128/aac.46.9.3020-3025.2002

[12] Routh MD, Zalucki Y, Su C-C, Long F, Zhang Q, Shafer WM, et al. Efflux pumps of the resistancenodulation-division family: A perspective of their structure, function, and regulation in gram-negative bacteria. Advances in Enzymology and Related Areas of Molecular Biology. 2011;77:109-46. https://doi.org/ 10.1002/9780470920541.ch3

[13] Handing JW, Ragland SA, Bharathan UV, Criss AK. The MtrCDE efflux pump contributes to survival of Neisseria gonorrhoeae from human neutrophils and their antimicrobial components. Frontiers in Microbiology. 2018;9:2688. https://doi.org/10.3389/ fmicb.2018.02688

[14]. Boston University Research Support. Neisseria Gonorrhea Agent Information Sheet [Internet]. Www.bu.edu. [cited 2021 Jul 14]. Available from: https://www.bu.edu/researchsupport/safety/rohp/agentinformation-sheets/neisseria-gonorrhea-agentinformation-sheet/
[15] University of Washington Environmental Health and Safety. Biosafety Level 2 (BSL-2) Laboratory Practices [Internet]. Washington.edu. [cited 2021 Jul 14]. Available from: https://www.ehs.washington.edu /system/files/resources/BSL2-info.pdf

[16]Zhang Y. The CRISPR-Cas9 system in Neisseria spp. Pathogens and Disease. Oxford University Press; 2017;75(4). https://doi.org/10.1093/femspd/ftx036

[17] Carr IM, Morgan JE, Diggle CP, Sheridan E, Markham $\mathrm{AF}$, Logan $\mathrm{CV}$, et al. Illuminator, a desktop program for mutation detection using short-read clonal sequencing. Genomics. Academic Press. 2011;98(4):302-9. https://doi.org/10.1016/j.ygeno.2011 .05 .004

[18] Doudna, JA, Charpentier E. Genome editing. The new frontier of genome engineering with CRISPR-Cas9. Science. 2014;346(6213):1258096. https://doi.org/ $10.1126 /$ science. 1258096

[19] McGinnis S, Madden TL. BLAST: At the core of a powerful and diverse set of sequence analysis tools. Nucleic Acids Research. 2004;32. https://doi.org/ 10.1093/nar/gkh435

[20] Addgene. CRISPR Guide [Internet]. Addgene.org. [cited 2021 Jul 14]. Available from: https://www.addgene.org/guides/crispr/

[21] Pichler M, Coskun ÖK, Ortega-Arbulú A-S, Conci N, Worheide G, Vargas S, et al. A 16S rRNA gene sequencing and analysis protocol for the Illumina MiniSeq platform. MicrobiologyOpen. 2018;7(6):e00611. https://doi.org/10.1002/mbo3.611

[22] Tsvetkov D, Kolpakov E, Kassmann M, Schubert R, Gollasch M. Distinguishing between biological and technical replicates in hypertension research on isolated arteries. Frontiers in Medicine. 2019;6:126. https://doi.org/10.3389/fmed.2019.00126

[23] Blair JMA, Piddock LJV. How to measure export via bacterial multidrug resistance efflux pumps. mBio. 2016;7(4). https://doi.org/10.1128/mBio.00840-16

[24] Driehuis E, Clevers H. CRISPR/Cas 9 genome editing and its applications in organoids. American Journal of Physiology-Gastrointestinal and Liver Physiology. 2017;312:G257-65. https://doi.org/10.1152/ajpgi.00410.2016

[25] Coculescu BI. Antimicrobial resistance induced by genetic changes. Journal of Medicine and Life. 2008;2(2):114-123. Available from: https://www.ncbi.nlm.nih.gov/pmc/articles/PMC30189 $\underline{821}$

[26] Gianecini R, Irazu L, Rodríguez M, Cristaldo P, Oviedo C, Turco M, et al. Testing of in vitro susceptibility of Neisseria gonorrhoeae to azithromycin: Comparison of disk diffusion and reference agar dilution methods. Journal of Clinical Microbiology. 2020;58(11). https://doi.org/10.1128/ $\underline{\text { JCM.01398-20 }}$ 
UNDERGRADUATE RESEARCH IN NATURAL AND CLINICAL SCIENCE AND TECHNOLOGY (URNCST) JOURNAL

Read more URNCST Journal articles and submit your own today at: https://www.urncst.com

[27] Hudzicki J. Kirby-bauer disk diffusion susceptibility test protocol. 2009. Available from:

https://asm.org/getattachment/2594ce26-bd44-47f6$\underline{8287-0657 \mathrm{aa} 9185 \mathrm{ad} / \text { Kirby-Bauer-Disk-Diffusion- }}$ Susceptibility-Test-Protocol-pdf.pdf

\section{Article Information}

Managing Editor: Jeremy Y. Ng

Peer Reviewers: Jordan Donders, Siobhan O'Brien

Article Dates: Received May 14 21; Accepted Jul 20 21; Published Aug 2721

\section{Citation}

Please cite this article as follows:

Jackson KA, Ayoub T, Pearson JE, Richmond JA. Combating antimicrobial resistance: Assessing efflux pump deficient environments in Neisseria gonorrhoeae and the masking effect on antimicrobial-resistant mutations. URNCST Journal. 2021 Aug 27:5(8). https://urncst.com/index.php/urncst/article/view/281

DOI Link: https://doi.org/10.26685/urncst.281

\section{Copyright}

(C) Kaitlyn A. Jackson, Tiffany Ayoub, Julia E. Pearson, Julie A. Richmond. (2021). Published first in the Undergraduate Research in Natural and Clinical Science and Technology (URNCST) Journal. This is an open access article distributed under the terms of the Creative Commons Attribution License (https://creativecommons.org/licenses/by/4.0/), which permits unrestricted use, distribution, and reproduction in any medium, provided the original work, first published in the Undergraduate Research in Natural and Clinical Science and Technology (URNCST) Journal, is properly cited. The complete bibliographic information, a link to the original publication on http://www.urncst.com, as well as this copyright and license information must be included.
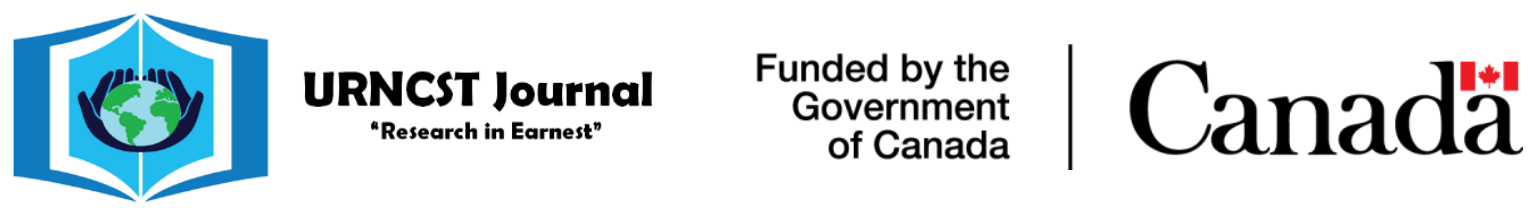

Do you research in earnest? Submit your next undergraduate research article to the URNCST Journal!

| Open Access | Peer-Reviewed | Rapid Turnaround Time | International | | Broad and Multidisciplinary | Indexed | Innovative | Social Media Promoted |

Pre-submission inquiries? Send us an email at info@ urncst.com | Facebook, Twitter and LinkedIn: @URNCST Submit YOUR manuscript today at https://www.urncst.com! 